\title{
Symbolism of Auto-Descriptions of Modern Human: Anthropology as a Narrative Ontology
}

\author{
Pavlo Kretov
}

\author{
Candidate of Philological Sciences, Associate Professor, Cherkasy Bohdan Khmelnytsky \\ National University (Cherkasy, Ukraine) \\ E-mail: ataraksia@ukr.net \\ ORCID: 0000-0003-2593-3731
}

\section{Olena Kretova}

\author{
Candidate of Pedagogical Sciences, Associate Professor, Cherkasy Bohdan Khmelnytsky \\ National University (Cherkasy, Ukraine) \\ E-mail: ekretova@ukr.net \\ ORCID: 0000-0002-3947-4479
}

\begin{abstract}
The purpose of the article is to investigate the content of the principal intentions of interpreting the symbol in the context of the anthropology of culture and philosophical anthropology and their correlation with the functioning of the semantic field of culture. The scientific originality of the article is presented by the study of the correlation between the consideration of the aspect of nature and the specificity of the symbol in autoscripting human practices within the philosophical projects representing these cognitive positions. The article substantiates the position on the ontologizing of the symbol in modern cultural and philosophical anthropology and the significance of convergence of the notion of the symbol with the concepts of the object and the thing. The cognitive potential of the conception of narrative ontology and its connection with the problematics of philosophical anthropology is emphasized. The importance of ontological turn in cultural anthropology for the philosophical anthropology is mentioned. The potential of the ontological turn in philosophical anthropology for the contemporary philosophy of education and comprehension of the newest ideological models interpreted as open and nonlinear systems is stressed. The correlation between the declared interpretation of the symbol and the project of object-oriented ontology and the modern philosophy of science is specifically considered. The conclusions of the article determine the specific character of being of the symbol in the communicative sphere of the modern man, social space, for the construction of identity and self-positioning of the modern individual.
\end{abstract}

Keywords: symbol, auto-description, philosophy of education, philosophical anthropology, functionalism, representationalism, relativism, object, thing, ontologizing, narrative

Received: July 9, 2018; accepted: September 5, 2018

Future Human Image, Volume 10, 2018: 29-40.

DOI: $10.29202 / \mathrm{fhi} / 10 / 3$

\footnotetext{
(C) Kretov, Pavlo, 2018

(C) Kretova, Olena, 2018
} 


\section{Introduction}

The relevance of the topic is due to the modern research on symbolic and social anthropology [Balibar \& Miller, 2017; Keesing \& Haug, 2012; Osipov, 2009; Holoh, 2015], social philosophy [Ross, 2009; Tabachkovsky, 2005; Sycheva, 2000], the philosophy of education [Bazaluk, 2010, 2013, 2015], the symbolic philosophy of culture [Barash, 2008], and problematization of the situation of "ontological turn" in various anthropological approaches to the interpretation of concept of the symbol in the ontological, communicative, functional, representational, and relational contexts. The importance of it is determined, first of all, by the need for search and creation of a modern worldview model that would harmonize the intentions of contemporary philosophy, fundamental science within the forms of consciousness established by them and correlations between these forms. In the same context, attempts are being made to rethink the so-called "temporal regime" of the sensory-generative matrix of modernism and postmodernism [Assmann, 2017], under which the procedurality of speech and the reception of texts or a language (the situation within which any proposition is a latent performative judgement according to the performative hypothesis of John Ross and Anna Wierzbicka [Susov, 2009]) occurs in the present (permanent "now") ontologized universal time of human subjectivity. This means going beyond any metaphysical superstructures and the above-mentioned Foucault's Grand Narrative — if semantics within a correlation of major fields of semiotics can be included in pragmatics, then propositions or sentences or words are not "objects, functions, or qualities, but types of linguistic Act" [Barker, 2004]. According to the following approach, syntactics ceases to be a set of disengaged from the pragmatic content of logical forms. Essentially, exactly semantic, conceptual aspect of the description of reality under such conditions is not paramount. Speech acquires the status of not just a marker of being (inquam, ergo sum) - it is a being itself. Hence, the project of narrative ontology appears. The myth and glossolalia return to the authorized discourse of philosophy and science, leaving nature reserves (or ghettos) of genre specifications in fiction and stylistic constructions in the discourse. Namely, it refers to the model of the worldview, which is extremely close to the open nonlinear complex system. The choice of the theme is also connected with the relevance of the question of the nature and the mode of functioning of the symbol and the mental structure which captures the correlation the thing — the symbol — the philosopheme of the symbol that form a new peculiar "semiotic triangle" (Charles Ogden, Ivor Richards) as an epistemological construct and a cognitive model for the cognitive field of modern humanities, and in a broader sense - in the dimension of ontology that constitutes this field as a whole. The scientific originality of the article is represented by the study of the correlation between the consideration of the aspect of nature and the specificity of the symbol in the symbolic autodescription of a man within philosophical projects (in particular, the narrative ontology) that represent these cognitive positions and the present state of the communicative field of society, the existence of symbols in it and the emphasis on the ontological nature of the symbol.

The purpose of the study is to examine and analyze the changes in the interpretation of the symbol in the context of the ontological turn in the anthropology of culture and philosophical anthropology and their correlation with the functioning of the semantic field of human consciousness and culture. 


\section{Discursive Dimension of Philosophical Anthropology}

It is noteworthy that the correlation between them to a certain extent is foreseen in the significant texts for the postmodern paradigm of the late 70's and early 80's of the last century, one of which belongs to the tradition of the Frankfurt school of German social philosophy, and the other to the French post-structuralism - we are talking about "Criticism of the cynical mind" (1983) by Peter Sloterdijk and "Ego sum: corpus, anima, fabula" (1979) by Jean-Luc Nancy that was recently published in English translation in 2016. Sloterdijk and Nancy interpret the crisis of the subject of traditional metaphysics in different ways. First thinker dreams to see

"...the tree of the dying philosophy blossoming again — in a blossom that does not disappoint, full of spectral flowers of thoughts, red, blue, white ones that radiate colors of the beginning when during the time of the Greek spring when theoria arose, and incomprehensibly and suddenly, like everything clear, understanding has developed its language" [Sloterdijk, 2002: 18].

Another philosopher argues that: "I say I am, and this is the same thing — to be, in order to speak at least", he thinks about the verb to be as transitive, transitional which means that "human Dasein is found in it, it transitively exists in its own essence, and this transitivity is given only in a statement or in a word" [Nancy \& Morin, 2016: 8].

As we notice this is about a performative judgment, about speech which acquires the ontological status of an event, an object and things (Demarcation of such meanings is inherent in the conceptual structure of the language). For instance, in the common Greek dialect, the Koine which the New Testament was written with, is detached in the sense of terms such as logos and rhema as the expressed word (in the meaning of the sentence, judgment) and the word being spoken (in the meaning of the event, act)). We can say that both thinkers emphasize the necessity of a semantic generative glossolalia (we understand this as a certain sacramental "revelation" of the language through speech) for philosophical discourse and space of thinking against the background of tragic unspeakable lack of expression within the impassable categorical system of old metaphysics, overcoming the schematics which formed the basis of the project of phenomenology of Edmund Husserl, and the fundamental ontology of Martin Heidegger in the early $20^{\text {th }}$ century.

Vadim Rudnev in his work "A New Model of Reality" (2016) proposes an epistemological model which is the basis for a new ontology as well, which the author himself defines as a narrative one. At the center of his rational constructions lies the long-standing author's thesis of the "contradistinction" of reality, moving in time towards entropy and text which moves in time towards the accumulation of information. Thereby the scientist compares the reality of the perceived "objective" world and the reality of the plot in its storyline and linguistic dimensions [Rudnev, 2016: 4]. The explicit schematics of such a model is removed by the researcher due to the intuition that these many-sided motions have a general tendency to merge. To illustrate this, the philosopher, the psychologist and the literary critic uses the classic metaphor of the "Möbius stripes" which is a direct appeal to the algebraic and geometric topology (we should mention a classic example with a bagel and a cup, a Klein bottle, a Borromeo node, Maurits Escher's structures, Penrose's mosaic and etc., up to the self-similar fractal structures in general) and demonstrates unclosedness, openness and decentralization as the defining features of the project of narrative ontology. 


\begin{abstract}
"Since the internal and external processes on the Möbius strip always change places, the elements of the new model of reality "resist" (Gilles Deleuze expression) in constant transformation, penetration into each other and identification with each other" [Rudnev, 2016: 5].
\end{abstract}

The researcher almost claims that since the narrative appears as a conceptual myth (Olga Freidenberg) then in modern conditions it is a concrescence of all possible ways of describing the reality and methods of interacting with it. Moreover, the situation gets complicated by the extreme problematization and complication of the notion of communication due to the challenging issues of AI and digital culture and civilization (if the concept of digital communication in its distinctiveness with the analogue of Paul Vatslavik is accepted as a general one [Knyazeva, 2014]). Therefore, we are dealing not only with the syncretism of the archaic myth but with the new integrity, that claims to be all-encompassing, refusing it at the same time. The infinite number of personal narratives, life stories and collisions, motives and storytelling, phrases and narratives form a peculiar rhizome (Gilles Deleuze) but it has a new order and new properties, going beyond the notions and symbols of rhizome, and the metaphor of the fold of the symbol which envelops the reality while emerging from it, in which the outer and inner surfaces cannot be separated, as in the classical object of the topology. Consequently, any description and the worldview picture based on it are quite close to the narrative, and hence to the newest myth. Yet Wittgenstein's attempts to construct a grammar of the description (in the "Treatise") of reality, which predetermined the development of the theory of speech act, had latently retained a certain moment of mythologism as a hypostasized narrative. Moreover, these considerations refer to the humanities and to the language of science in general, since a holistic model of descriptionunderstanding-experience of the world by a man is based on the following understanding of the speech and also the possibility of forming both autonomous and heteronomous variants of ethics as a practical philosophy according to modern American researcher [Meretoja, 2014]. The linguistic description, therefore, comes to end, whereas the narrative, predicting the final end, doesn't necessarily mean it, furthermore it can be cyclical or recursive; in other words, the narrative is an endless fairy tale of Scheherazade in which Self is a sultan and a slave as well. In addition, modern hermeneutics of the text does not deny the pathos of fragmentation and nihilism of the negation of postmodernism, protecting the relevance of "narrative understanding" as a model of the present [Owen, 2011], and this model relies on the "personal voice" of an individual who opposes schematism and generalization, uniting in the sense the narrative "phenomenology and aesthetics, the traditions of continental and Anglo-American philosophy founded on Ludwig Wittgenstein, John Austin, Immanuel Kant, Søren Kierkegaard and Martin Heidegger” [Kenaan, 2005]. Therefore, it should be addressed that if there is no logical valence in the content of propositional guidelines according to Gottlob Frege (since it has only in itself, within the structure but not in the content, syntactics prevails over the semantics), then within the narrative, interpreted ontologically, when syntactics and semantics are extremely close to pragmatism on the general background of the performative judgment as the major model of the formation of the meaning [Barker, 2004], "reality has nothing to do with truth or falsehood" [Rudnev, 2016: 7], and that is precisely because it is conceived within (which is not really the limit - let's recall the Mobius strip) the narrative, semantic model of reality. The thing within the narrative ontology reveals the connections of its conceptual and categorical certainty, since its continuity is not determined in the static coordinate system of metaphysical concepts and categories. In 
the speech which is implicitly a performative act, any "categories of being" of linguistics or the philosophy of language overcome as the rationalized constructs of another metalanguage and notional recursiveness. Thus, the subject of philosophical anthropology becomes now a narrative ontology of a man as his symbolic auto-description.

\section{Theoretical Paradigms of Symbolic Interpretations of the World Picture}

Let us examine some initial concepts. Under representationalism we mean the traditional notion of the so-called naive realism in epistemology, according to which the experience of human consciousness is not identical to reality as such, but only its representation. In accordance with the theme of our article, we proceed from the established philosophy of the late $20^{\text {th }}$ century (Nelson Goodman, Richard Rorty) the concept of the symbolic nature of constructing reality in the mind which relates not only to the reality of religion and art, but also the scientific picture of the world. We comprehend the functionalism in the tradition of contemporary philosophy of consciousness (Hilary Putnam, Daniel Dennett), according to which the functional interpretation of reality as dependent one on the "mental dictionary" which is not wearing out by the phenomenal qualities of the objects of the world of consciousness or physical events of the external material world, postulates algorithmic structure of the functions of information processing by the brain within the consciousness. Therefore, functionalism hypothetically overcomes the distinction of consciousness and matter, since functional states and models can be implemented in the material substrate (brain structures) and in the strictly ontological conceptions as well, those ones that presuppose the existence of the spirit, the autonomous ontological space of consciousness and so on. Finally, relativism we will interpret as epistemological one that denies the absolute (closed and immutable) character of the philosophical categories of the scientific picture of the world of empirical perceptions and sensory representations. In this sense, the starting point for us is the concept of "ontological relativity" by Willard Quine where the theory is stated as a formulated system of language, and objects whose existence implies the theory, are interpreted as the referents of language, thus the reality is what the language asserts about it, and vice versa, while the referents of the language terms are the objects of the ontology of this language.

It should be pointed out that in relation to all three mentioned theoretical positions the notion of a symbol turns out to be relevant - this can be said about the symbolic interpretation of the representation of reality and the symbolism of functional series (for instance, in the most radical version of functionalism within the philosophy of consciousness - the modular concept of consciousness by Jerry Phodor), and the symbolic interpretation of the object (referent), which is nearly identical with being and existence in the relativism of Willard Quine and Donald Davidson. That is why the philosopheme of the symbol seems to be not merely a unifying concept, but a meaning-generational model (Alexey Losev), or a rhizomatic object for the formation of meaning for the culture (Gilles Deleuze), an original "matrix of meaning" that heuristically allows to address the available cognitive field of philosophical anthropology. Hence, a stated tendency in cultural anthropology claims to build a new reading of ontological and epistemological issues in the context of the search of philosophical anthropology. But if we take for major definition not a modern interpretation of metaphysics as a strictly intelligible discipline that is devoted to the study of being as such, but as a science which main purpose is to describe the human conceptual structures [Loux, 2006: 496], then this tendency also 
applies to metaphysical knowledge which is not briefly investigated within the framework of the contemporary British-American analytic paradigm in philosophizing, but in general the entire Western tradition, including the Platonic (ontologizing) and Aristotelian (semiotic) intentions in regards to the essence of the sign, the Augustinian doctrine of the symbol ("De doctrina christiana"), the modern, first of all, Kantian intentions as for the interpretation of the space between the object or the subject of the indicating, the symbol and the designator, or to the meaning overall that is produced by symbolic epistemology. If the sign (symbol) and the thing do not necessarily have to be different entities, and we are not aware how one thing is known through another (either a logical conclusion, or the examining of the relation between the referent and the sign, or the mere substitution of the referent by the sign - Alexey Losev devoted a whole section in his book on the distinction of a symbol and cognitive structures which are similar to each other, but it is not a symbol [Losev, 1995; Bibikhin, 2007]). If we can dare to make an analogue in the spirit of the contemporary philosophical trend which is marked as "neurophilosophy" between the already mentioned Ogden-Richards semiotic triangle which is genetically derived from Charles Pearce, and the Holy Grail of cognitive neurophysiology - interaction within the triangle "neuron-axon-synapse" in the so-called trigger zone, then it becomes clear the complexity of defining the mechanism of cognitive activity is not exclusively descriptive at the level of neurophysiology, but from the point of view of ontological and semantic problematics. The claimed considerations are also significant for the modern philosophy of education, since its pyramidal structure (Boris Bim-Bad) [Bazaluk, 2015] implies the basis for a holistic and syncretic (but not mythologized in the archaic sense) human discourse and self-understanding and self-identification.

"A large-scale vision of social transformations and worldview concepts that are dominant during this historical period, among which the planetary-cosmic space one is worth pointing out" [Bazaluk \& Yukhymenko, 2010: 12], — this is what the pedagogy is enriched by the philosophy of education according to modern researchers.

In addition, since the modern era of paradigm shift causes a situation that

"...there are raptures in traditions and the need for new worldview meanings occur, philosophy develops them. It summarizes the created, discovered, reproduced in a coherent picture and presents the world as a system in which everything known about the world takes its place at the present moment. Philosophy forms a harmonious, generalized picture of the world, in which the place of the man, the organic and inorganic world are clearly indicated" [Bazaluk, 2013: 98].

It should also be mentioned in this context the intentions of the research of modern scholars, which determine the vectors of the movement of transformation of the socio-cultural sphere in general and discourse-communicative practices in particular. These changes take place in the field of university studies ("University as a social technology" [Pavlova, 2018] and modern practices of understanding and interpreting large arrays of texts based on digital communication technologies [Bogataya, 2018]. The relevance of the symbolic model of the generation of meaning is now relevant.

On the other hand, the Max Sheler's tradition of philosophical anthropology as a study of a human being - a special type of reality in the context of the philosophical problems of the 
anthropic principle in non-classical and post-classical science refers to the possibility of a new synthesis in humanities after all, on the basis of system-founding knowledge and discursive constructions (descriptiveness of reality) of fundamental science.

\section{Symbolic Explication of Modern Human}

Attempts in the order to rely on the philosopheme of the symbol to come closer to comprehension of the concept of consciousness, a man in general, as previously noted, are extremely ancient. However, it is about the rise of the symbolic philosophical anthropology at the moment in which the predication of the symbolism is explained not instrumentally or functionally, but ontologically.

"This is a modality on the basis of which a person builds relationships with any creature, subject, situation", — writes the modern Italian researcher Davide Navarriya in his book "Symbolic Anthropology" [Navarriya, 2016: 195].

Thereby, the symbol reveals the hidden meanings of things not in the form of deductive and formalized knowledge, which is final at a certain stage, even on recursive sequence. The symbol, symbolism and the symbolic attach man to the meanings, while implementing it, directly - ontologizing it. The symbol is the mirror of self-realization. The fact that contemporary psychoanalysis or its variants, such as existential or cognitive psychology (Rollo May, Bert Hellinger), interpret symbolic practices as practices-for-Self, exactly Self, not for any conditional, postulated within the limits of scientific or philosophical essentialism of reality, is an evidence of the ontologizing potential of symbolism. Therefore, the symbolism within the frames of symbolic anthropology is a way to go beyond the limits of the language and actually, beyond the boundaries of grammar and structure, thus it proposes an alternative to rational-logical and discursive way of capturing the meaning. The well-known call of Ludwig Wittgenstein "Do not Think and See" (Philosophical Investigations, 66) is a way to be now, hence, to engage in the infinitude of the symbolic series of being, it does not matter how we interpret it: as a space of consciousness, the reality of cultural meanings, material world of objects and so on. Continuing our analogy between semiotics, symbolic anthropology and neurophysiology, we can make the symbolic ranks similar to the neural networks of the human brain and hypothetical AI - they are the ones who predetermine the open code of the assemblage of reality, namely it enables the interaction of consciousness (organized within the limits of the semiotic code of the language, for example) and the brain - software and hardware. How is this reading of the symbol and symbolic possibly given in the field of social communication (for instance, the media space and the alternative reality of social networks) in the space of self-determination and self-identification of a person as a cognitive agent? To begin with we must emphasize that the symbolic way of fixation of the knowledge underlies any semiotic code (because a language is the variant of such an invariant, then hypothetically any sign, representation, perception that has symbolic potential can be transformed into the symbol) and therefore has a direct relation to the practical philosophy in the traditional Kantian sense, since it becomes as an intermediary between the unconditionality of the categorical imperative and the inevitable mortality of a human being [Bielefeldt, 2003]. When we talk about the symbolic landscape of society or the phenomenological aspect of Lebenswelt, we mean that this is not just a background, 
this is the way and the place of ontological rooting of human beings, his self-identification with the domain of meanings and in the very thesaurus of the culture's meanings. Namely, it simultaneously performs (launches) a self-transcendental function for a person, it is external as for the individual and is inherent to him, indicating a way to overcome the limitations of the myth of the given (myth of the given by Wilfrid Sellars). Contemporary American researcher Marc Ross, discussing the application of the symbolism in "divided societies", observes that the symbolic form of the expression of meaning simultaneously acts as a barrier or the possibility of the person's will to choose, recognition of his own identity at all the levels - from ethnic to cultural and political, and it provides an opportunity to judge, it turns out to be a criterion for the degree of tension in a particular society [Ross, 2009: 4]. In this manner, modern wars for the consciousness practically use all the language symbols as the main arsenal (it functions as the instruments; a sword or a weapon or a tool? The concept of the arsenal is already referring to the connotations associated with war, violence) are predetermined by the symbolic means - from simple linguistic symbolism to complex operating on the pre-logical and pre-verbal symbolic levels of the picture of the world. Since self-determination and self-identification take place mainly in the social context, then the means of this self-determination are inherently symbolic — symbols are "the building blocks of self-determination" [Kashima, 2002]. It is significant that the means of the optimization and therapy for such societies are also symbolic because the symbol, due to the moment of interaction between the elements within its structure, generates a dramatic effect, which may have cathartic orientation, appealing to the empathy and emotions [Schirch, 2005]. The modern researcher of media culture Anthony Adler observes that the hyper-consumerism of the culture of the 21 st century mainly involves the visualization of meanings in the virtual dimension of various informative resources based on images and video chain which is up to TV, the content of resources such as YouTube, the diversity of social networks that triggers a new crisis of a phenomenological approach to substantiating ontological problems [Adler, 2016]. In fact, it refers to the tendency to radicalize the understanding of being as a random and chaotic one. Other researchers point out that modern philosophical anthropology problematizes the symbolic nature of the subject's socialization and the rise of a symbolic citizen [Balibar, 2017]. As follows, we can assume that the symbolism of the media space for contemporary philosophical anthropology is not just a marker of the specifics of the current situation and the epiphenomenon of the progress of science and technology development, so to speak, in the premonition of technological singularity (Vernor Vinge), but the basis of social being and the formation of ideas about the identity of a man in being and society. Accordingly, the symbolization of being (a symbol as an Ariadne's thread for a man in the chaos of instant, unexperienced, non-rooted meanings) is associated with a desymbolization.

\section{Symbol: Ontologizing Categories and Concepts}

Let us consider the correlation of the symbol and the notion of a thing, which is relevant to the ontological turn in the cultural and philosophical anthropology mentioned above. We are now interpreting the thing, not as an object within the traditional subject-object dichotomy, but not as a subject neither (rather something that opposes the subject) in the context of dialectics of the philosopheme of a thing proposed by Martin Heidegger in classical text of the late period of activity "Thing" (1954). When the thinker speculates that the major purpose for a thing is to be itself to the fullest emanation which is its ontological status anyway, he therefore argues 
against not only Aristotle and his teleology of the final cause, but also with Kantian dualism, falling into an original Western philosophical Zen, establishing the thing through emptiness (example with a cup), but not identifying them. When a philosopher writes about a spoiled thing [Heidegger, 1971: 167], he defines the predication of putridity as a loss of functionality (constantly falling cup), but he also means that

“...the capacity of the thing rests not in the material from which it is composed with, but in the emptiness that holds. Is the cup really empty?" [Heidegger, 1971: 167].

Finally, without going into detail of the Heidegger's concepts [Sycheva, 2007], we can conclude that a broken thing for a philosopher is such a thing which clarifies its true nature and uncovers its "state of thingness" by abandoning predetermined functions. It is noteworthy that in the $21^{\text {st }}$ century within the theoretical direction of speculative realism (Graham Harman, Quentin Meillassoux, Ben Woodard, Yoel Regev), "object-oriented ontology" Graham Harman, based on this tradition, interprets ontological objects as principally larger than simple sum of components, qualities, relations (for instance, the superadditivity). If an object is always superfluous in relation to what it does at a current point under our observation [Harman, 2005], then it is not equal to the sum of the effects that it can cause, because it may cause new, yet unknown effects in the future. Consequently, Garman's object escapes from conceptual fixation and credible knowledge like the Heidegger's thing, because it is smaller than the hypothetical sum of the effects and is larger than the sum of its parts. The object is changeable, shimmering (that is how thinker Pavel Florensky defined a symbol in the early 20 century) as we see as at the intersection of thoughts of thinkers, we return to the philosopheme of the symbol again. Vladimir Bibikhin argues that the Heideggerian thing is not a symbol for two reasons:

"...it is not an image, but the very presence of the world, the world is present in the thing not as a semantic prospect, but as its own essence" [Bibikhin, 2007: 429].

Thus, the thing is a being in its own "state of thingness" but a symbol, besides being a meaning-generating model, also has an indicative function, implementing its own being and its own symbolic dimension of being, and in this case, the symbol can be compared with a thing in Heidegger's tradition and it is an object in the object-oriented ontology of Graham Harman. In order to illustrate the presence of such a latent understanding of the symbol in the Western philosophical tradition, we can refer to all the European Platonism, to the philosophical and theological concept of Signatura Rerum, furthermore, the symbolic function of the objects in conceptions of Ernst Cassirer, Susanne Langer, Mircea Eliade, Jane Duran, Davide Navarriya acquires a vividly pronounced ontologizing. It is necessary to mention the latest work by Vladimir Lefebvre "What Is An Animate?" (2014) where the scientist addresses the question of the ontological status of the model in science and the nature of the reality behind it. The philosopher of science practically states that ideal thinkable (physical) objects can have a status of really existing ones. This is virtually about, according to the scientist,

"...the dissociation of the ontological boundaries of reality through returning to the ideas of Plato" [Lefebvre, 2014: 10]. 
Recalling in this context Alexius Meinong's non-existent real objects, we notice that the intention of contemporary science and philosophy is to rethink the status of an object towards its expansion. Object, thing, subject of research, thinkable object, symbol, cognitive model of consciousness, epistemological constructs - all these concepts acquire new connections and relations, cause new effects, complicating the cognitive and ontological situation of a man. On the other hand, this tendency can be considered a movement towards overcoming, for instance, a speculative realism of correlationism, in which a person is always between the reality and thinking, but never deals with reality itself. In connection with that, a performative judgment as the central notion of narrative ontology can overcome the dichotomy of thing and its semblance, true and untrue, the consideration of thing and its simulacrum. And in this sense, the main achievement of the phenomenological approach consists in an accentuation and analysis of the symbolic functional of thing which is within the semiotic code of the language which makes a foundation (but does not limit) the space of the thought and, according to the cognitive (conceptual) semantics, determines it, means a return to the "magic", performative meanings and the senses of the spoken word.

\section{Conclusions}

Symbolic auto-description for a modern man in conditions of rapid socio-cultural dynamics and technogenic background of development of human civilization is a relevant modus of formation of the existential identity, as well as the fundamental basis of preserving a person's own self. Modern humanities which actually problematize these processes, actualizes for this purpose among others and the project of narrative ontology, as a synthesis of achievements of neurophysiology, cognitive psychology and linguistics, culture studies, philosophy of education and philosophical anthropology.

The concept of the symbolic landscape in regards to the social philosophy and philosophical anthropology in the modern conditions of the information society and the impetuous changes in the socio-cultural background, connected primarily with the new intensive forms of producing, perception and processing of information is gaining new significance. The situation in which the information is disseminated instantaneously, the content cannot be critically analyzed by the recipient (because of its volume and its principled anonymity) leads to the fact that reality ceases to be symbolic only as a logical predicate, but the symbol becomes a reality, approaching the philosopheme, a thing and an object.

Representationism, functionalism and relativism mentioned in the title of the article indicate a triangulation scheme of defining the concept and phenomenon of the philosopheme of the symbol for contemporary philosophizing, since these cognitive models capture the symbolic aspects of the phenomenological, formal-logical, linguistic, cultural, hermeneutical dimensions of the explanation of reality by a man and his place in it, the construction of a picture of the world as a scientific and personally-holistic one, such that provides selfawareness and self-positioning of man.

The modern philosophy of education, in an effort to comprehend the aftermaths of the logocentrism and phonocentrism in the field of educational methodology, can rely on a holistic model of human consciousness that it proposes contemporary neurophilosophy based on neurophysiology, psychology, pedagogy and cognitive linguistics. The determinative feature of this model can be an absence of a strict gradation between different types of consciousness (everyday, philosophical (metaphysical), scientific, 
religious, mythological) which correspond to the correlative types and models of speech and the creation of discourse. Perhaps, under this condition, scientific consciousness, the scientific picture of the world will acquire new forms of correlation with the seemingly antagonistic invariants of the world and auto-descriptions, for instance, mythological or religious, foremost, in the sphere of the existential dimension of human life, where a person is formed in general.

In the modern philosophy of culture and philosophy of science, it is possible to stress a certain paradox: the symbol, ontologizing, is interpreted as an object or a thing, but still continues to operate as a conceptual symbolic construction (or conceptual metaphor (Joseph Campbell)). Hence, the symbolic reality ceases to be a reality of the second order, but the circle of endless autorecursion is not closing up (postmodern criticism tried to make a reduction of a symbol). Thus, a virtual culture and science of the $21^{\text {st }}$ century postulate the ontology of virtual reality, in which only the symbols are able to return a thesaurus of phylogenetic civilizational memory to a person, to root it, because the symbols, gaining ontologizing, proclaim to the person about herself, and not only infinitely provide a person with multilevel semantic ranks, or it refers to something different. Ontologizing of a symbol means that it is not just real, but it creates a specific type of reality.

\section{References}

Adler, Anthony. Celebricities: Media Culture and the Phenomenology of Gadget Commodity Life. New York: Fordham University Press, 2016.

Assman, Aleyda. "The connection of times broke up?" The rise and fall of the temporal regime of Modernity. Moscow: New Literary Review, 2017.

Balibar, Étienne, and Steven Miller. Citizen Subject: Foundations for Philosophical Anthropology. New York: Fordham University Press, 2017.

Barash, Andrew. The Symbolic Construction of Reality: The Legacy of Ernst Cassirer, Chicago: University of Chicago Press, 2008.

Barker, Stephen. Renewing Meaning: A Speech-Act Theoretic Approach. Oxford, England Clarendon, 2004.

Bazaluk, Oleg. Postmodernism: the Philosophy of Education. Future Human Image, Volume 2(5), 2015: 9-23.

Bazaluk, Oleg, and Iliana Vladlenova. Philosophical Problems of Cosmology. Kharkov: "Textbook" Publishing House of Kharkiv University of HTI, 2013.

Bazaluk, Oleg, and Nataliya Yukhymenko. Philosophy of Education. Kyiv: Condor, 2010.

Bibikhin, Vladimir. The language of philosophy. Moscow: Science, 2007 (in Russian).

Bielefeldt, Heiner. Symbolic Representation in Kant's Practical Philosophy. New York: Cambridge University Press, 2003.

Bogataya, Lidiya. Culture of National Philosophical Communities: the Project Dedicated to the Research of Modern Ukrainian Philosophical Traditions. Future Human Image, Volume 9, 2018: 20-26.

Harman, Graham. Heidegger on Objects and Things. Making Things Public. Bruno Latour \& Peter Weibel (eds.). MIT Press, 2005.

Heidegger, Martin. The thing, [in:] Martin Heidegger. Poetry, language thought. Translations and introduction by Albert Hofstadter. New York: Harper \& Row, 1971: 161-185. 
Holoh, Olena. Hermeneutics of human existence in the symbolic anthropology of K. Girce. Bulletin of Kyiv National Technological and Economic University, Volume 3, 2015: 72-86.

Kashima, Yoshihisa, Foddy, Margaret and Platow, Michael. Self and Identity: Personal, Social, and Symbolic. Mahwah (NJ): Lawrence Erlbaum Associates, 2002.

Keesing, Roger and Haug, Jordan. On not understanding symbols: Toward an anthropology of incomprehension. Journal of Ethnographic Theory, Volume 2 (2), 2012: 406-430.

Kenaan, Hagi. The Present Personal: Philosophy and the Hidden Face of Language. New York: Columbia University Press, 2005.

Knyazeva, Elena. Enactivism: a new form of constructivism in epistemology. Moscow: University Book, 2014 (in Russian).

Loux, Michael. Metaphysics. A contemporary introduction. Kyiv: Spirit and letter, 2006.

Lefebvre, Vladimir. What Are Consciousness, Animacy, Mental Activity and the Like? Los Angeles: Leaf \& Oaks Publishers, 2014.

Losev, Alexey. The problem of the symbol and realistic art. Ed. by A. A. Taho-Godi. Moscow: Art, 1995 (in Russian).

Meretoja, Hanna. Narrative and Human Existence: Ontology, Epistemology, and Ethics. New Literary History. The Johns Hopkins University Press 1, Volume 45, 2014: 89-109.

Nancy, Jean-Luc and Marie-Eve Morin. Ego Sum: Corpus, Anima, Fabula. New York: Fordham University Press, 2016.

Navarriya, Davide. Symbolic anthropology. A religious man and his sacred experience. Kyiv: Spirit and letter, 2016.

Osypov, Anatoliy. Wisdom and Symbol in Spiritual Practices: Abstract ... D. philosopher. sciences, Specialty: 09.00.04 — Philosophical Anthropology, Philosophy of Culture. Kharkiv: H.S. Skovoroda Kharkiv National Pedagogical University, 2009.

Owen, Hana. M. Bakhtinian Thought and the Defence of Narrative: Overcoming Universalism and Relativism. Cosmos and History: The Journal of Natural and Social Philosophy, Volume 7 (2), 2011.

Pavlova, Olena. Classic University as Institutional Form of Human Action. Future Human Image, Volume 9, 2018: 92-99.

Ross, Marc. Culture and Belonging in Divided Societies: Contestation and Symbolic Landscapes. Philadelphia: University of Pennsylvania Press, 2009.

Rudnev, Vadim. New model of reality. Moscow: Higher School of Economics, 2016 (in Russian).

Schirch, Lisa. Ritual and Symbol in Peacebuilding, Bloomfield (CT): Kumarian Press, 2005.

Sloterdijk, Peter. Criticism of the cynical mind. Kyiv: Tandem, 2002.

Susov, Ivan. Linguistic pragmatics. Vinnytsia: The New Book, 2009.

Sycheva, Svetlana. Martin Heidegger on things, symbols and thinking, Bulletin of Tomsk State University, Volume 297, 2007: 84-91 (in Russian).

Tabachkovsky, Vitaliy. Multisubstance homo: philosophical and artistic thought in search of “non-Euclidean reflexivity”. Kyiv: PARAPAN, 2005. 